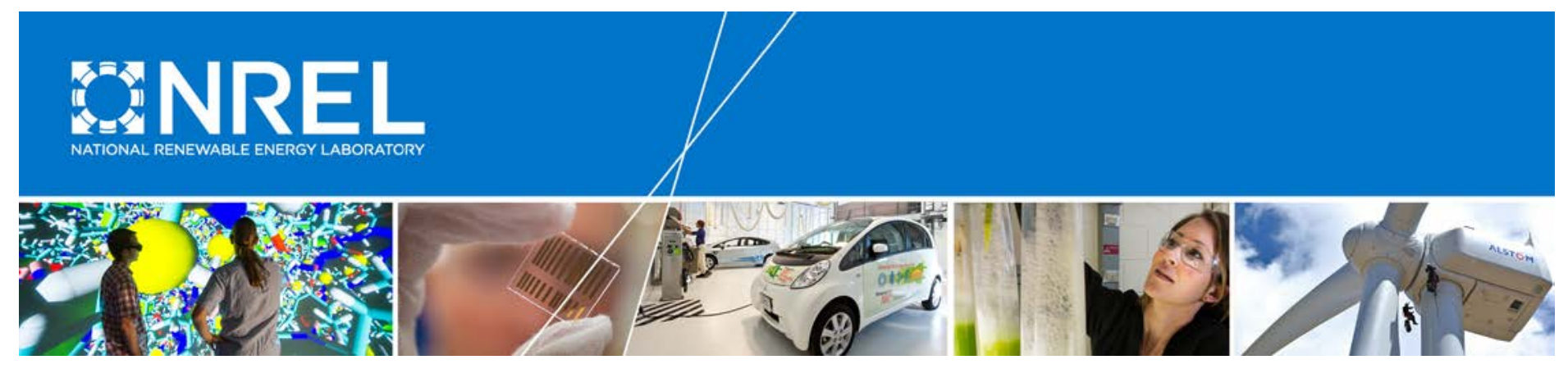

\title{
An Opportunistic Wireless Charging System Design for an On-Demand Shuttle Service
}

\section{Preprint}

\author{
Kate Doubleday, Andrew Meintz, \\ and Tony Markel
}

Presented at the 2016 IEEE Transportation Electrification Conference and Expo (ITEC 2016)

Dearborn, Michigan

June 27-29, 2016

(c) 2016 IEEE. Personal use of this material is permitted. Permission from IEEE must be obtained for all other uses, in any current or future media, including reprinting/republishing this material for advertising or promotional purposes, creating new collective works, for resale or redistribution to servers or lists, or reuse of any copyrighted component of this work in other works.

NREL is a national laboratory of the U.S. Department of Energy Office of Energy Efficiency \& Renewable Energy Operated by the Alliance for Sustainable Energy, LLC

This report is available at no cost from the National Renewable Energy Laboratory (NREL) at www.nrel.gov/publications.

\section{Conference Paper}

NREL/CP-5400-66090

August 2016

Contract No. DE-AC36-08G028308 


\section{NOTICE}

The submitted manuscript has been offered by an employee of the Alliance for Sustainable Energy, LLC (Alliance), a contractor of the US Government under Contract No. DE-AC36-08GO28308. Accordingly, the US Government and Alliance retain a nonexclusive royalty-free license to publish or reproduce the published form of this contribution, or allow others to do so, for US Government purposes.

This report was prepared as an account of work sponsored by an agency of the United States government. Neither the United States government nor any agency thereof, nor any of their employees, makes any warranty, express or implied, or assumes any legal liability or responsibility for the accuracy, completeness, or usefulness of any information, apparatus, product, or process disclosed, or represents that its use would not infringe privately owned rights. Reference herein to any specific commercial product, process, or service by trade name, trademark, manufacturer, or otherwise does not necessarily constitute or imply its endorsement, recommendation, or favoring by the United States government or any agency thereof. The views and opinions of authors expressed herein do not necessarily state or reflect those of the United States government or any agency thereof.

This report is available at no cost from the National Renewable Energy Laboratory (NREL) at www.nrel.gov/publications.

Available electronically at SciTech Connect http:/www.osti.gov/scitech

Available for a processing fee to U.S. Department of Energy and its contractors, in paper, from:

U.S. Department of Energy

Office of Scientific and Technical Information

P.O. Box 62

Oak Ridge, TN 37831-0062

OSTI http://www.osti.gov

Phone: 865.576.8401

Fax: 865.576.5728

Email: reports@osti.gov

Available for sale to the public, in paper, from:

U.S. Department of Commerce

National Technical Information Service

5301 Shawnee Road

Alexandria, VA 22312

NTIS http://www.ntis.gov

Phone: 800.553 .6847 or 703.605 .6000

Fax: 703.605.6900

Email: orders@ntis.gov 


\title{
An Opportunistic Wireless Charging System Design for an On-Demand Shuttle Service
}

\author{
Kate Doubleday \\ Andrew Meintz \\ and Tony Markel \\ National Renewable Energy Laboratory \\ Golden, Colorado 80401
}

\begin{abstract}
System right-sizing is critical to implementation of in-motion wireless power transfer (WPT) for electric vehicles. This study introduces a modeling tool, WPTSim, which uses onesecond speed, location, and road grade data from an on-demand employee shuttle in operation to simulate the incorporation of WPT at fine granularity. Vehicle power and state of charge are simulated over the drive cycle to evaluate potential system designs. The required battery capacity is determined based on the rated power at a variable number of charging locations. Adding just one WPT location can more than halve the battery capacity needed. Many configurations are capable of being self sustaining with WPT, while others benefit from supplemental stationary charging.
\end{abstract}

\section{INTRODUCTION}

A hurdle in the widespread adoption of electric vehicles (EVs) is the tradeoff between battery capacity and the available trip range. Dynamic inductive wireless power transfer (WPT), which occurs while the vehicle is in motion, can address both problems by delivering power to the point of use [1], [2]. Similarly, opportunity charging uses WPT at consistent stop locations to take advantage of longer dwell times to recharge the vehicle. These systems are being applied in amusement park trolleys or municipal buses with predictable, frequently repeated routes [3], [4]. The National Renewable Energy Laboratory (NREL) is pursuing such a system for the laboratory's employee shuttle to reduce the campus footprint and develop a platform for further research. The purpose of this study is to investigate key considerations in right-sizing the system, including battery capacity and the number and location of ground transmitter coils.

Previous studies of the Online Electric Vehicle (OLEV) system modeled allocation of infrastructure for vehicles with a predetermined route and set velocity profile, while requiring vehicles to fully charge at each WPT location before resuming service [5]-[7]. As expected for opportunity charging in this application, the optimal WPT locations generally overlap with bus stops [7]. Like these systems, the NREL shuttle is isolated from external traffic and travels at low speed, but unlike these scenarios, route and speed are not predetermined. The shuttle regularly circulates around a central loop through campus, but the exact timing and location of stops are based on employee demand and deviations to peripheral locations are not uncommon. Rather than assuming a simplified speed profile, this study is based on actual position and velocity data

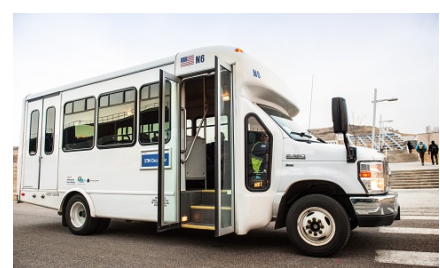

(a)

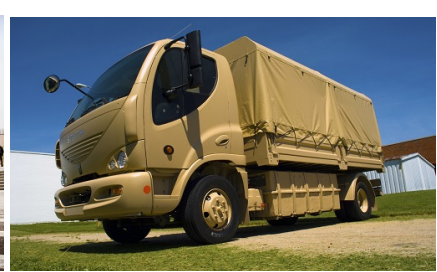

(b)
Fig. 1. (a) Conventional Ford Startrans employee shuttle. (b) Electric Smith Newton stake bed truck. Photos from Dennis Schroeder (NREL 32221) and Smith Electric Vehicles (NREL 17631)

recorded from the shuttle in operation. The future shuttle will not be required to reach full charge at any point in its route, but rather, the goal is to be charge sustaining over the course of a week without constraining the shuttle's operation.

\section{Methods}

Each of the two 12-passenger 2012 Ford Startrans shuttles (Fig. 1a) travels approximately 55-65 miles per day transporting employees around NREL's campus, with a combined average daily boarding of 360 passengers. It is desirable to replace these vehicles with WPT-capable all-electric shuttles, simulated here as a Smith Electric Vehicles Newton modified to emulate the size of the Startrans. A vehicle dynamics model accounting for input power from WPT is used to evaluate a variety of system designs for replacement of the Startrans to determine the best combinations of battery capacity, charging location, and charging power for the NREL application. The data collection, simulation, and validation are described below.

\section{A. Simulation Input Data}

The simulation requires three inputs at each time step: position, speed, and road grade. For the first two, an existing shuttle was equipped with an Isaac DRU908 data logger for five days in January and February 2015 to record global positioning system (GPS) data and SAE-J1979 onboard diagnostics from the OBD-II port at a 1-second time resolution. These data are combined to simulate a sample work week. Fig. 2 shows the shuttle's route over one work day. Based on the frequency of stops at key locations where passengers board, three locations are identified as candidates for wireless charging stations: the parking garage, the Research Support 


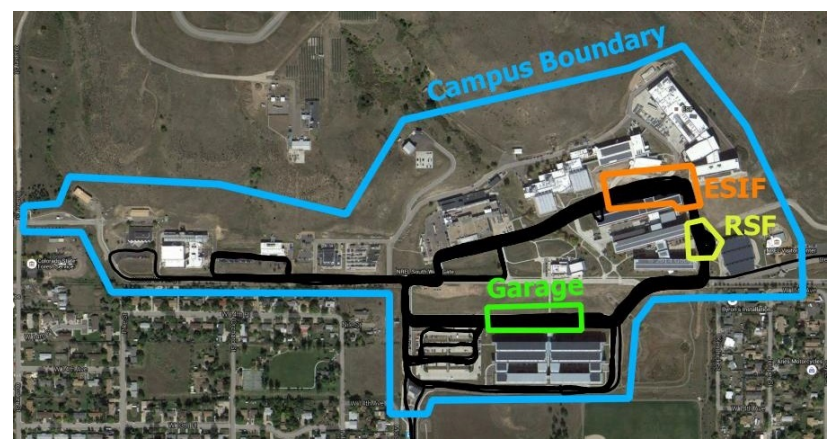

Fig. 2. Map of the NREL campus, indicating the three selected locations for WPT. The black line marks the shuttle's route for a single work day. Imagery and map data @2016 Google.

Facility (RSF), and the Energy Systems Integration Facility (ESIF). Outside the designated campus boundary, the vehicle is assumed to be at rest.

Road grade can be estimated from the change in elevation between sequential data points, but due to the uncertainty of a given GPS location, the resulting data have clear inconsistencies. To address this issue, two methods are employed for estimating road grade on the most commonly traveled campus roads: in regions where road plans are available from recent construction, grade is read off the plot and applied to all data points that lie between the closest inflection points. In other regions, the grade data derived from GPS location is averaged over all data points for a particular road segment to smooth out inconsistencies. Shuttle travel outside of the highlighted areas is simulated with 0 grade as the travel on these segments is so infrequent that the authors assume grade will have a negligible impact on the overall results. Fig. 3 shows the resulting grade estimates, overlaid with a few hours of the shuttle's route.

\section{B. WPTSim Model Description}

A MATLAB-based simulation of battery power and state of charge (SOC) over the drive cycle, WPTSim, is utilized to compare potential system designs. WPTSim employs the Future Automotive Systems Technology Simulator (FASTSim), a previously developed vehicle dynamics model, to determine the power required at each one-second time step using a spectrum of vehicle-specific parameters characteristic of a Newton [8]-[10]. Table I lists the key time-dependent simulation variables. For a given total battery capacity, $E_{\max }$ and maximum usable $\mathrm{SOC}, S O C_{\max }$, battery stored energy and SOC are calculated as:

$$
\begin{gathered}
E(t)=E(0)-\int_{0}^{t} P_{E S S}(\tau) d \tau \\
S O C(t)=E(t) / E_{\max }
\end{gathered}
$$

assuming $E(0)=S O C_{\max } \times E_{\max }$. Whenever $S O C(t)$ reaches $S O C_{\max }$ due to WPT, regenerative braking, or static charging, FASTSim will no longer accept additional charge.

WPT is incorporated into the model by simulating each WPT region with a transmitter rated at $P_{\text {rated }} \in$

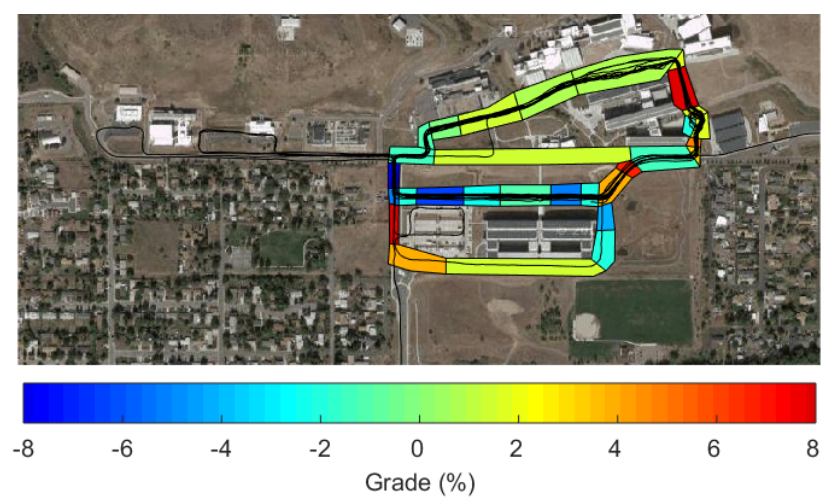

Fig. 3. Blocks of average road grade, shown with a few hours of travel data Data points that fall within a block are assigned the corresponding grade. Imagery and map data (C2016 Google.

TABLE I

Simulation VARIABLES FOR EACH TIME STEP $t$

\begin{tabular}{lll}
\hline$v(t)$ & $(\mathrm{mph})$ & Recorded vehicle speed \\
$v_{\text {ach }}(t)$ & $(\mathrm{mph})$ & Vehicle speed achieved in simulation \\
$g(t)$ & $(\%)$ & Road grade \\
$L(t)$ & $(\mathrm{Lat} / \mathrm{Lon})$ & Vehicle location \\
$P_{E S S}(t)$ & $(\mathrm{kW})$ & Battery output power \\
$E(t)$ & $(\mathrm{kWh})$ & Battery stored energy \\
$S O C(t)$ & $(\%)$ & Battery state of charge \\
$P_{r e c(j)}(t)$ & $(\mathrm{kW})$ & Power coupled into receiver $j$ \\
\hline
\end{tabular}

$\{20,40,60,80,100\} \mathrm{kW}$. It is assumed that the transmitters will be visibly marked for the shuttle drivers. Therefore, during each pass through a given WPT region, the location where the shuttle stops for the longest time is assumed to be at the center of the transmitter coil. As shown in Fig. 4, the shuttle can be simulated with $m=1$ to 5 receivers at 40 $\mathrm{cm}$ spacing, each of which capture up to $20 \mathrm{~kW}$; all five are required to make full use of a $100-\mathrm{kW}$ transmitter. For explanation purposes, Fig. 5 shows example data based on [11] where coupling power between the transmitter and a receiver varies with displacement. In the current study, the transmitter is modeled after the OLEV system using proprietary OLEV coupling data along the length of the coil, though a robustness study of lateral displacement has not been included in this work. At every time point, $d_{j}(t)$, the displacement of receiver $j$ from the transmitter, is determined and the coupled power $P_{c}(d)$ at that displacement is looked up from the vector of coupling data. It is assumed there is no start-up delay in energizing the transmitter, so full power is available as soon as a receiver is in proximity. The input power from WPT is calculated as the sum of the power coupled into the receivers while the vehicle moves a distance $l$ during the step from $t-1$ to $t$ :

$$
P_{W P T}(t)=\sum_{j=1}^{m} P_{r e c(j)}(t)
$$

To calculate the power $P_{r e c(j)}(t), P_{c}\left(d_{J}\right)$ is numerically integrated at $1-\mathrm{cm}$ resolution using a linear interpolation of 


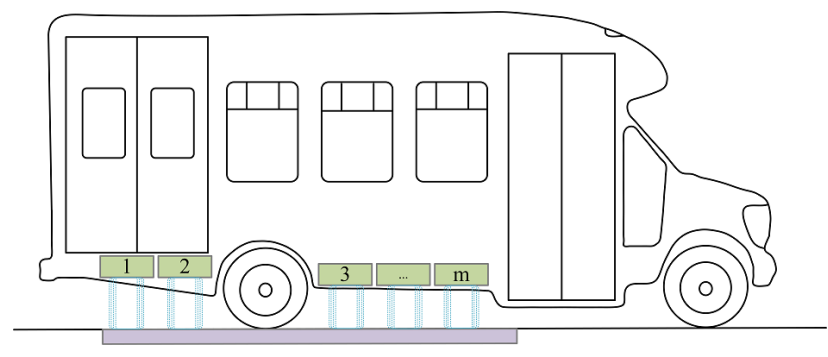

Fig. 4. The shuttle is simulated with $m$ vehicle receiver coils (green), which couple to the ground transmitter coil (blue). For a 100-kW transmitter, $m=5$ $20-\mathrm{kW}$ receivers are required to capture the maximum power

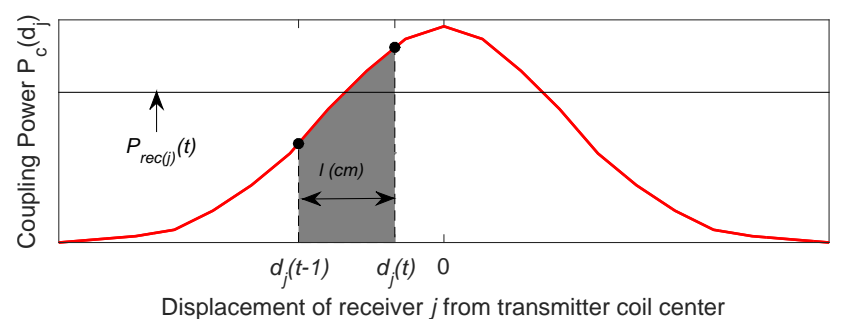

Fig. 5. The power coupled into one receiver at time point $t$ is calculated as the average power received over the time step, assuming near-constant speed as the vehicle moves a distance $l$.

the OLEV coupling data by assuming a constant speed over each 1-second time step:

$$
P_{r e c(j)}(t)=\frac{1}{T} \int_{t-1}^{t} P_{c}\left(d_{j}(\tau)\right) d \tau \approx \frac{1}{l+1} \sum_{k=0}^{l} P_{c}\left(d_{J}(k)\right)
$$

The simulation approach is to split the drive cycle into $i=1,2, \ldots n$ segments, each extending from starting time $t_{\text {start }, i}$ to ending time $t_{\text {end, } i}$, based on vehicle speed, position, and SOC. Each segment is given one of four types that dictates the algorithm that will be applied by the co-simulation between WPTSim and FASTSim: (1) driving without WPT, (2) driving with WPT, (3) parked, or (4) parked with stationary charging (optional). As shown in Fig. 6, the data are segmented as follows: if the GPS location is outside the NREL boundary or the speed is 0 for at least a 30-minute period, the vehicle is considered to be parked. If stationary charging is desired, type 4 segments begin 10 minutes after the vehicle parks and conclude 10 minutes before the vehicle resumes driving or when the vehicle reaches $S O C_{\max }$, whichever is sooner $t_{\text {end }, i}$ is initially estimated, then the exact time is determined during the co-simulation. While the vehicle is driving or temporarily stopped within NREL boundaries, it is either driving without WPT (type 1) or driving with WPT (type 2) if its GPS position also coincides with a WPT region defined in Fig 2.

Once the drive cycle has been segmented, each segment is co-simulated according to the following rules:

$$
\begin{aligned}
& \text { if } \operatorname{type}(i)=1 \text { then } \\
& P_{E S S}(t) \text { and } v_{a c h}(t) \text { calculated by FASTSim }
\end{aligned}
$$

else if $\operatorname{type}(i)=2$ then

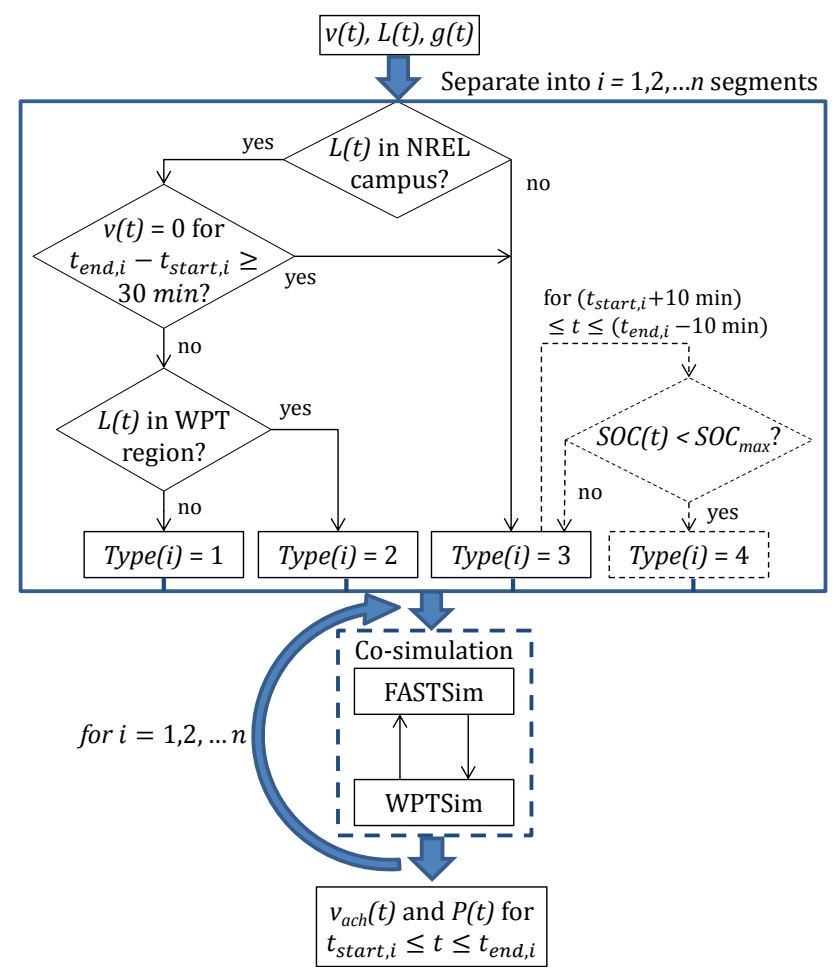

Fig. 6. Simulation block diagram

TABLE II

EleCtric ShutTle PARAMETERS

\begin{tabular}{lll}
\hline$M$ & Vehicle mass without battery & $6,800 \mathrm{~kg}$ \\
$M_{B} / k W h$ & Additional battery mass [12] & $100 \mathrm{~kg} / \mathrm{kWh}$ \\
$S O C_{\min }$ & Minimum usable SOC & $10 \%$ \\
$S O C_{\max }$ & Maximum usable SOC & $90 \%$ \\
$P_{\text {aux }, \text { on }}$ & Auxiliary load while driving & $5 \mathrm{~kW}$ \\
$P_{\text {aux }, \text { off }}$ & Auxiliary load while stationary charging & $0.1 \mathrm{~kW}$ \\
$P_{\text {static }}$ & Stationary charger power & $20 \mathrm{~kW}$ \\
\hline
\end{tabular}

$P_{E S S}(t)$ and $v_{a c h}(t)$ calculated by FASTSim, incorporating $P_{W P T}(t)$ calculated by WPTSim

else if $\operatorname{type}(i)=3$ then

$$
\begin{aligned}
& P_{E S S}(t)=0 \\
& v_{a c h}(t)=0 \\
& \text { else }\{\text { type }(i)=4\} \\
& \quad P_{E S S}(t)=-\left(P_{\text {static }}-\frac{P_{\text {aux }, \text { off }}}{E f f_{12 V}}\right) \times \sqrt{E f f_{E S S, R T}} \\
& v_{\text {ach }}(t)=0
\end{aligned}
$$

where $E f f_{E S S, R T}$ is battery round trip efficiency and $E f f_{12 V}$ is $12-\mathrm{V}$ converter efficiency. For conductive charging, it is assumed the battery SOC increases linearly and there is no taper in charging power as the battery nears $S O C_{\text {max }}$. Table II lists the vehicle parameters, which have been modified to simulate the proposed electric shuttle, sized to the current Startrans shuttle, as well as the remaining stationary charging parameters.

Battery capacities $E_{\max } \in\{20,40,60,80,100,120\} \mathrm{kWh}$ are considered. Therefore, the total vehicle weight is calculated as:

$$
M_{t o t}=M+M_{B} / k W h \times E_{\max }
$$




\section{RESULTS}

\section{A. Parameter Validation without WPT}

To validate the battery efficiency and motor parameter inputs to the model, a Smith Newton stake bed truck (Fig. 1b) was used to compare simulated to actual battery power over a typical shuttle drive cycle by driving the stake bed truck behind the campus shuttle. GPS and battery power data were collected from the onboard diagnostic system of the Newton during the four-hour test drive in October 2015. Average grade was applied as before. These data were then simulated as described above to verify the vehicle dynamics parameters accurately capture the behavior of this vehicle. The simulation parameters of Table II were modified to reflect the vehicle's known battery capacity $E_{\max }$, idling auxiliary load $P_{a u x, o n}$, and total weight $M_{t o t}$, verified at a weigh station. The simulated battery energy used was within $0.4 \mathrm{kWh}$ of the actual battery data at all points in the drive cycle. Additionally, $v(t)$ and $v_{a c h}(t)$ differed at fewer than $0.1 \%$ of points, indicating the power and energy constraints chosen are acceptable to meet the drive trace. Therefore, the authors conclude that the chosen model parameters will give an accurate estimation of the behavior of a heavier Newton-type vehicle with the required shuttle body and upfit.

\section{B. Electric Shuttle Simulations}

Simulation results of the proposed WPT-capable electric employee shuttle confirm that no single WPT location at the assumed power levels is sufficient to sustain the battery over the course of the day. However, the opportunistic charging method takes advantage of the complementary usage patterns at the chosen WPT locations. As Fig. 7 shows, the garage is best for morning charging when employees are arriving, while the RSF is best in the afternoon while the shuttle waits for passengers returning to their vehicles to leave campus. WPT at both locations maintains SOC throughout the day. The ESIF is useful in late morning when shuttle drivers park there for breaks.

By combining the five days of data into a sample work week, static charging can be incorporated at lunch and night as shown in Fig. 8. It is important to note that with no WPT, the vehicle requires a 140-kWh battery, which is not in Smith's product catalog at present [10]. As a simple example of the benefits of WPT, by adding an $80-\mathrm{kW}$ transmitter at the garage, the battery capacity can be reduced by more than half, to 60 kWh.

To compare a range of system designs, 216 scenarios are simulated given all combinations of $P_{\text {rated }}$ at the three wireless charging locations. The number of receivers ranges from one to five and is determined by the maximum $P_{\text {rated }}$ of the three locations. The required minimum battery capacity is determined iteratively, starting with a $20-\mathrm{kWh}$ battery. If at any time the vehicle reaches $S O C_{\min }$, the simulation has failed, and the battery capacity is increased in $20-\mathrm{kWh}$ increments until the simulation is successful. The chosen battery capacity options are intentionally in coarse increments to reflect what

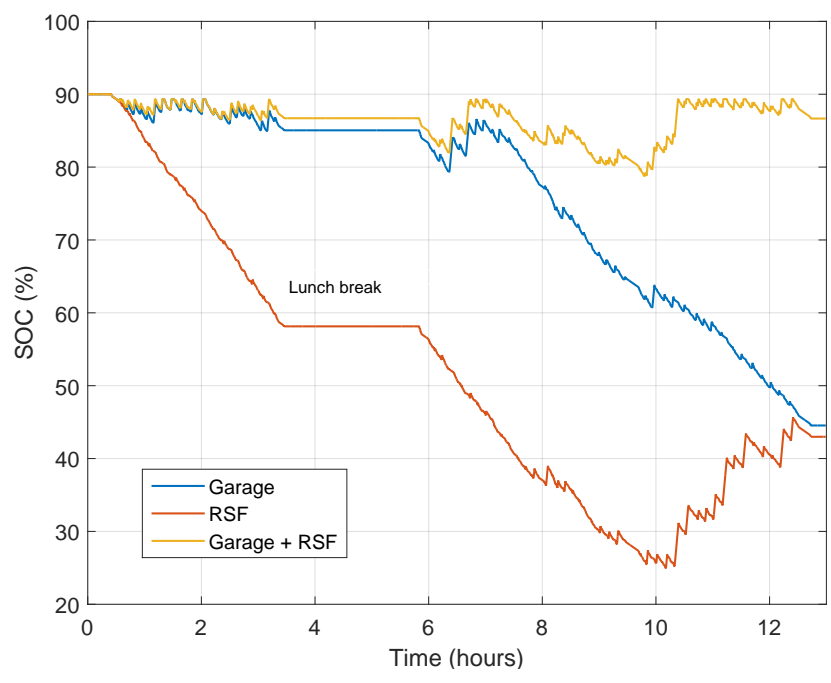

Fig. 7. SOC of the shuttle with a total $(0 \%-100 \%$ SOC) battery capacity of $100 \mathrm{kWh}$ over one work day. Each WPT location has a transmitter with a rated power of $100 \mathrm{~kW}$.

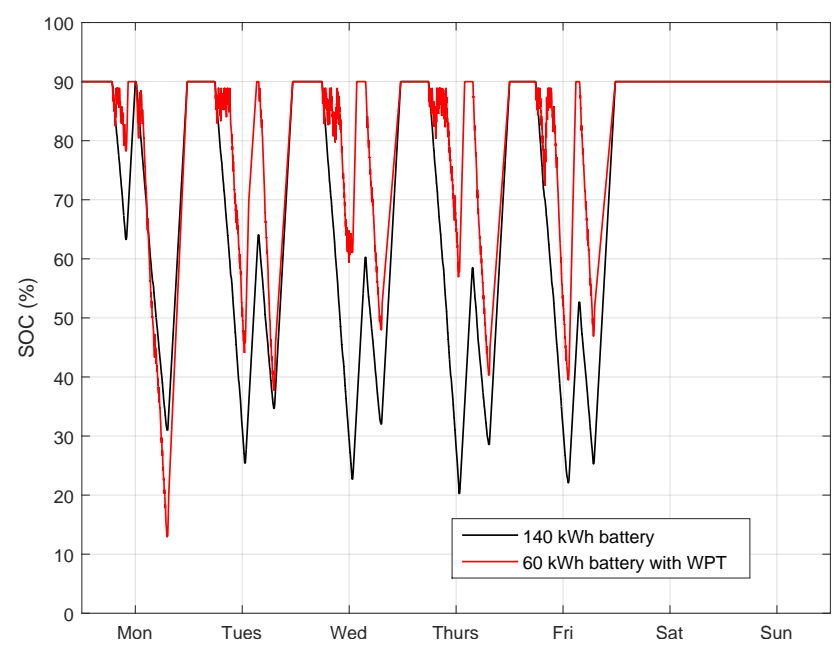

Fig. 8. SOC over a work week with $20-\mathrm{kW}$ static charging at night and lunch breaks. Adding an $80-\mathrm{kW}$ transmitter at the garage reduces the total battery capacity $(0 \%-100 \%$ SOC) by more than half.

is commercially available. Fig. 9 shows the required battery capacity as $P_{\text {rated }}$ ranges from 0 (no transmitter) to $100 \mathrm{~kW}$ at each WPT location. Adding WPT at any of the proposed power levels at any location would reduce the required battery capacity to $120 \mathrm{kWh}$ or less, which is within the range that is currently commercially available [10].

Fig. 10 shows the stationary charge time for each configuration. Battery capacity and reliance on static charging decrease as WPT infrastructure increases. An electric shuttle supported by both static and opportunistic wireless charging is certainly a viable option, particularly if two charging methods ensure system reliability and robustness. Fig. 11 shows the amount of usable battery capacity $(10 \%-90 \%$ SOC) that is unused due to the selection of battery capacity in fixed 20$\mathrm{kWh}$ increments. Excess capacity measures the built-in safety 


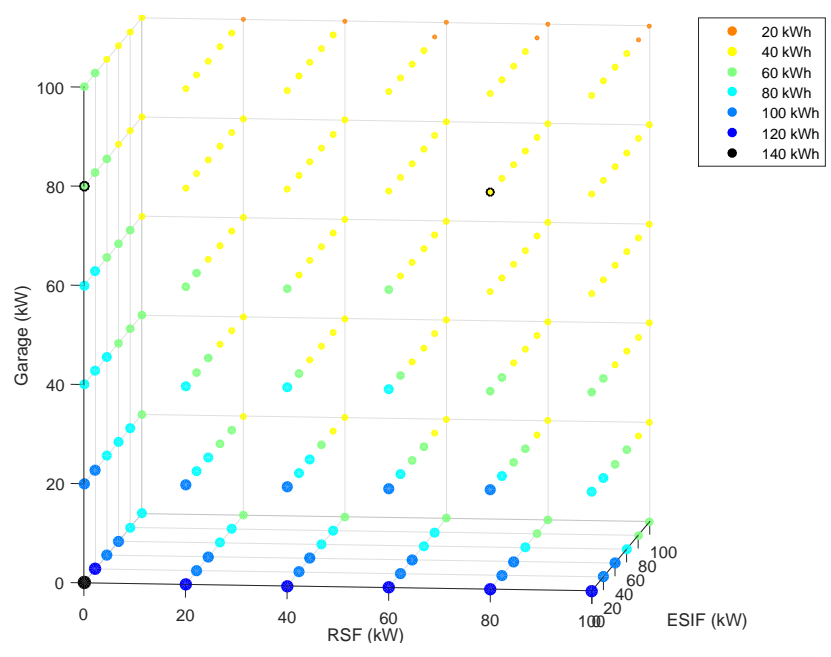

Fig. 9. Minimum required total $(0 \%-100 \%$ SOC) battery capacity decreases as the rated power $P_{\text {rated }}$ at each of three WPT locations increases from 0 to $100 \mathrm{~kW}$.

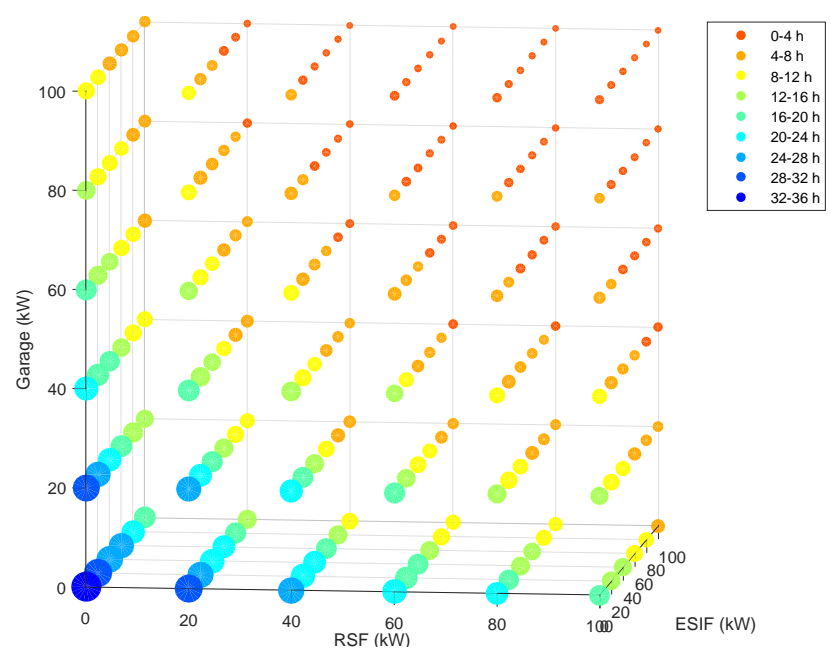

Fig. 10. Hours spent stationary charging per week

margin for uncertainty and battery degradation over the life cycle. As the battery capacity was selected based on the minimum required capacity at beginning-of-life, the excess battery capacity may not allow for battery capacity fade over its desired lifespan. Future study will investigate the impact of small, frequent WPT charging on battery life and modify the algorithm for selecting battery capacity to include battery life considerations.

A number of these scenarios have enough WPT capacity to support the vehicle with WPT alone, but the battery capacity may be increased again to compensate for the lack of static charging. Again, the correct battery capacity is determined iteratively by starting with the battery capacity in Fig. 9. If the simulation fails, the battery is increased to the next largest capacity, up to $120 \mathrm{kWh}$. A scenario that fails with a 120 $\mathrm{kWh}$ battery is not self-sustaining. If a scenario is successful at maintaining SOC over the work week, the end-of-week SOC is fed back into the following Monday as a double check

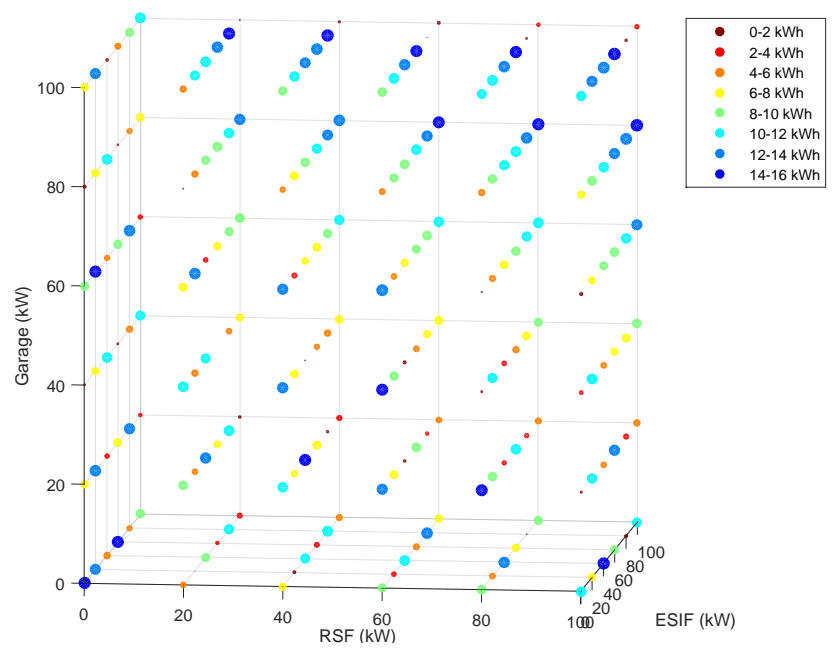

Fig. 11. Excess battery capacity, as a portion of the usable battery capacity $(10 \%-90 \%$ SOC)

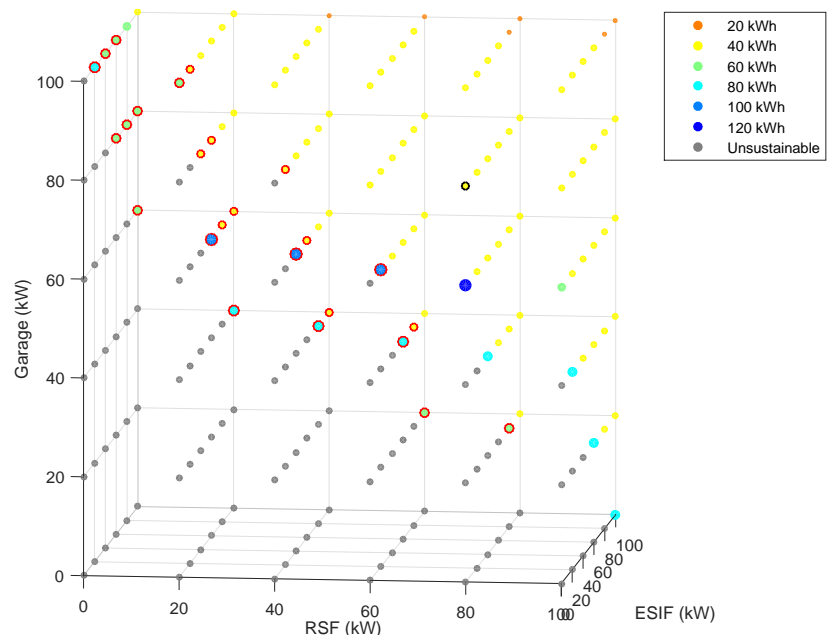

Fig. 12. Required battery capacity for self-sustaining WPT systems. Edge cases that failed the Monday double-check are outlined in red.

that the system is not gradually depleting SOC. Scenarios that pass this check are considered self-sustaining; those that fail the following Monday are edge cases in need of further consideration that likely require larger batteries. The results in Fig. 12 show many scenarios that support a $20-$ or $40-\mathrm{kWh}$ battery (Fig. 9) are already self-sustaining without needing to increase battery capacity.

By reviewing the results, a potential system implementation plan can be developed: starting with a single $80-\mathrm{kW}$ transmitter at the garage would enable the transition from a conventional to an electric shuttle with a $60-\mathrm{kWh}$ battery. This system would still rely heavily on supplementary stationary charging and would not be a good long-term option as there is little to no excess battery capacity. However, it may be a promising first step and test bed for continuing system development. Adding a second $80-\mathrm{kW}$ transmitter at the RSF would transition the system from unsustaining to self-sustaining with WPT alone, while only needing a $40-\mathrm{kWh}$ battery. These cases are circled 
in black in Figs. 9 and 12. Rather than reducing the battery to the $40-\mathrm{kWh}$ minimum, keeping the initial $60-\mathrm{kWh}$ battery would address the concern of long-term viability by increasing the excess usable capacity from 3 to $19 \mathrm{kWh}$, corresponding to an increase from $11 \%$ to $39 \%$ of usable battery capacity. While additional charging locations could be added, the results show that opportunistic charging at the RSF and garage is sufficient to support the shuttles, given their complementary usage patterns. A cost analysis would be required to determine whether more, lower power transmitters or fewer, higher power transmitters such as the two $80-\mathrm{kW}$ coils suggested here would be more economic.

\section{CONCLUSION}

This paper presents a novel tool, WPTSim, for evaluating both infrastructure and vehicle design scenarios toward converting a conventional fleet to WPT-enabled EVs. WPTSim simulates wireless power transfer at fine granularity using actual drive cycle speed, grade, and location data from conventional vehicles to compare WPT system design options. In contrast with previously published opportunistic charging system designs, this WPT system is fit to an on-demand shuttle without a fixed route and without artificial limitations to either its travel speed or the duration of its stops. By fitting the design to the current behavior, it is hoped that WPT can be seamlessly integrated into the rider's experience, rather than adding delays or hassle due to WPT. Validation of the FASTSim parameters using one-second time step data recorded from a Smith Newton stake bed truck shows good convergence between the actual and modeled vehicle energy use.

The goal of this case study was to use WPTSim to rightsize a WPT system for the NREL on-demand employee shuttle by selecting the number, location, and rated powers of the transmitter coils to minimize battery capacity. By sweeping the rated power at three potential charge locations, the minimum battery capacity and dependency on supplementary stationary charging were determined for each configuration. As an example implementation, an initial system with an $80-\mathrm{kW}$ transmitter at the garage can support a Smith Newton equipped with four receiver coils and a $60-\mathrm{kWh}$ battery. Upgrading the system by adding a second $80-\mathrm{kW}$ transmitter at the RSF can take the system from unsustaining to self-sustaining, with excess battery capacity for robustness and long-term viability. It is important to note that the reference case with no WPT requires a $140-\mathrm{kWh}$ battery, which is not currently commercially available. As a result, additional infrastructure will be required to electrify the shuttle, such as using two shuttles to cover the route before and after lunch or adding DC fast charging to top up during driver breaks. Alternatively, the desired wireless solution is to add even the lowest level of WPT at any of the charge locations, which can lower the required battery capacity to $120 \mathrm{kWh}$. For future study, incorporation of the vehicle's heating, ventilating, and air conditioning load into $P_{a u x, o n}$ will likely require an increase in battery capacity and restrict feasible system designs. Also left for future study is incorporation of battery life analysis into the selection process for right-sizing the vehicle battery.

\section{ACKNOWLEDGMENT}

This work was supported by the U.S. Department of Energy under Contract No. DE-AC36-08GO28308 with the National Renewable Energy Laboratory. The U.S. Government retains and the publisher, by accepting the article for publication, acknowledges that the U.S. Government retains a nonexclusive, paid-up, irrevocable, worldwide license to publish or reproduce the published form of this work, or allow others to do so, for U.S. Government purposes.

\section{REFERENCES}

[1] S. Choi, B. Gu, S. Jeong, and C. Rim, "Trends of wireless power transfer systems for roadway powered electric vehicles," in IEEE 79th Veh. Technology Conf. (VTC Spring 2014), May 2014, pp. 1-5.

[2] S. Chopra and P. Bauer, "Driving range extension of EV with on-road contactless power transfer - a case study," IEEE Trans. Ind. Electron., vol. 60, no. 1, pp. 329-338, Jan 2013.

[3] Utah State Today. (2012, Nov. 15) Utah State University Unveils Wirelessly Charged Electric Bus. [Online]. Available: https://www.usu. edu/today/index.cfm?id=51862

[4] C. Morris. (2014, Dec. 26) Scania to test wirelessly charged city bus in Sweden. [Online]. Available: https://chargedevs.com/newswire/ scania-to-test-wirelessly-charged-city-bus-in-sweden/

[5] Y. D. Ko and Y. J. Jang, "The optimal system design of the Online Electric Vehicle utilizing wireless power transmission technology," IEEE Trans. Intell. Transp. Syst., vol. 14, no. 3, pp. 1255-1265, Sept 2013.

[6] Y. J. Jang, S. Jeong, and Y. D. Ko, "System optimization of the OnLine Electric Vehicle operating in a closed environment," Comput. \& Ind. Eng., vol. 80, pp. 222-235, 2015.

[7] Y. Jang, E. Suh, and J. Kim, "System architecture and mathematical models of electric transit bus system utilizing wireless power transfer technology," IEEE Syst. J., vol. PP, no. 99, pp. 1-12, 2015.

[8] [Online]. Available: http://www.nrel.gov/transportation/fastsim.htm

[9] A. Brooker, J. Gonder, L. Wang, E. Wood et al., "FASTSim: A model to estimate vehicle efficiency, cost and performance," SAE Tech. Paper 2015-01-0973, 2015. [Online]. Available: doi:10.4271/2015-01-0973

[10] [Online]. Available: http://www.smithelectric.com/smith-vehicles/

[11] A. Zaheer, D. Kacprzak, and G. A. Covic, "A bipolar receiver pad in a lumped IPT system for electric vehicle charging applications," in IEEE Energy Conversion Congr. and Expo. (ECCE 2012), Sept 2012, pp. $283-$ 290.

[12] P. Nelson, K. Gallagher, I. Bloom, and D. Dees, "Modeling the performance and cost of lithium-ion batteries for electric-drive vehicles," 2nd ed. Chemical Sciences and Engineering Division, Argonne National Laboratory, Tech. Rep. ANL-12/55, 2012. 